\title{
NOT TEACHING, BUT COACHING CREATING A SELF-DEVELOPMENT CULTURE IN A CLASSROOM ${ }^{1}$
}

\author{
MONIKA GROCHALSKA \\ monika.grochalska@uwm.edu.pl \\ University of Warmia and Mazury \\ in Olsztyn, Poland
}

\begin{abstract}
Nowadays we hear a lot about coaching, but what does coaching really mean? Why does it matter? What is more, the notion of edu-coaching has also emerged in recent years, and this idea seems to be gaining popularity. But can coaching replace traditional classroom education? To what extent could it be useful at school?

In the first part of this article I would like to define what coaching is, how it is different from mentoring and how it can be used to support pupils and teachers at personal, team and whole school levels. Undoubtedly, there are obvious benefits of coaching for students, staff, school as well as coaches.

There are three core skills of coaching: listening, questioning and reviewing. To be a good coach, a teacher should understand how to be a good listener and how to ask proper coaching questions. They should ask questions that help them and the coached/the pupil to review, reflect and to clarify matters throughout the lesson.

There are some coaching tools that can be used at various stages of the coaching process at school, including the balance wheel, rating scale, bisociation, viewpoints and motivational record. A teacher can successfully use coaching on the basis of the GROW (Goal, Reality, Options and Will) model. It can support the teacher's development and his practice as a coach. As indicated in the on-line articles for teachers, starting professional training is also worthwhile.

During the training, a teacher can learn how to develop classroom practice that supports growth through the use of high level listening, questioning, reflecting and summarising. Most of professional training programs contain the following elements:

- using active listening and open questions to tackle issues such as pupil behaviour,

- reaching their full potential by putting in place realistic goals and plans to achieve them,

- taking responsibility for their own progress through change,

- building rapports that can turn previously difficult interactions into productive ones. Such skills allow the teachers to create a self-development culture in their classrooms.

I would like to ponder upon whether these theses have substantive grounds or perhaps they are just empty slogans. Can a teacher also be a good coach? Is it worthwhile to implement coaching in the education system? How can coaching help to improve classroom management?

These and some other issues will be considered in the following text.
\end{abstract}

Key words: coaching in education, self development, school

This article was written as part of the project funded by the National Science Centre allocated on the basis of the decision no DEC-2011/01/D/HS6/02470. 


\section{INTRODUCTION}

Currently, we hear more and more about coaching. But what is exactly meant by this term? Why has it become such an important and often emerging subject in the context of school education? The term edu-coaching has also been coined in recent years. And this idea seems to be increasingly popular. In recent years, a new coaching trend has been started in education and has become very fashionable. This fits into a broader concept, a phenomenon of infiltration of the trends from the world of adult commercial trainings to the school environment, noticeable in the past few years. The reasons for this phenomenon are not clearly recognized. Perhaps this is due to the fact that commercial training market is evolving rapidly towards meeting all the educational needs of clients and thereby maximizing the attractiveness of the learning process. Currently, schools must meet new requirements concerning liberalisation of the learning process and making it more attractive, hence it is not surprising that teachers are looking for inspiration where changes are progressing much faster.

However, inevitably the question arises to what extent these novelties are really useful in school education, and whether they are only a transient fashion, which does not contribute much to school environment. To what extent are teachers the beneficiaries of these changes, and do they bear only the costs associated with participation in consecutive trainings? Such questions come up every time when new alternative ways of teaching, learning and the possibilities of their use in the school environment are considered.

Coaching is a part of a wider social phenomenon that may conventionally be called the culture of self-development. The most important characteristics of this phenomenon are presented in the following sections.

\section{SELF-DEVELOPMENT CULTURE}

Basic beliefs behind the culture of (self)development pertain to the capabilities and conditions of today's development. First of all, this trend assumes that we all can improve and develop, but we are able to do it only if we want to, when we are prepared for it and truly involved. Today, we are well aware of the fact that not only our own beliefs, but also opinions of others about our abilities may affect our success. Our definition of success directly influences our performance. We limit our own abilities by our beliefs, e.g., we think that something is not possible due to external factors. We can learn from all our actions, but it requires personal reflection and a plan for the future. To help others in their development you do not need to be an expert, but you need to continuously develop yourself (Thorpe, Clifford, 2011, p 19).

This innovative approach to development is derived directly from the management theory. Old models of management (Giddens, 2012, pp. 366-393) used to control and treat employees like robots. However, ignoring the hearts and souls of employees by managers turned out to be a suicidal action. It is people who are the driving force behind the organisation. When organisations allow their employees to develop comprehensively, not only in the areas directly related to their duties, they 
contribute to the full utilization of the potential of these people in the work environment. A sense of involvement accompanied by flexible rules and schedule of the tasks is what makes people happy in their work. Provision of such conditions makes employees feel valued and allows them to deeply believe in their abilities. Modern organisations are investing more funds in staff development at the emotional, health, financial, intellectual, and spiritual levels than in the sole development of professional skills. This process can successfully combine employees' interest with organisation's goals. According to studies prepared by the Labour Offices, some of the most desirable competencies in the job market are (http:/ / www.wup.lodz.pl/ files/ciz/ciz_Nowoczesne_formy_rozwoju_pracownika.pdf,):

- communication skills,

- focus on achievements,

- teamwork,

- leadership,

- focus on the customer,

- flexibility,

- encouragement of the development of others.

Developing such skills is, therefore, satisfying employee's ambitions, as well as contributing to the development of the entire organisation. The improvement process can be seen as a part of the incentive system in the company. Employees often treat training as a reward or opportunity for professional development. One of the most widely used modern methods of employees improvement in the light of the aforementioned studies is coaching defined as a partnership relationship, in which "a coach helps his trainee to achieve desired success in personal and professional life. These objectives should be identified by an employee, but also agreed on with the coach" (Website of the Regional Labour Office in Lodz, http:/ / www. wup.lodz.pl/files/ciz/ciz_Nowoczesne_formy_rozwoju_pracownika.pdf). It is the coach who leads, motivates and inspires his client so that he can make positive changes in his life and perform at his best.

Creating a work environment that makes certain elements considered to be effective is causing their transfer to the public discourse, and from there they move to other environments, such as, e.g., schools. They begin to function as common elements of (self)development culture.

Development is widely understood and commonly defined as an introduction of positive changes in your personal and professional life, resulting in great satisfaction.

The issue is how useful coaching can be in the implementation of these changes and whether it contributes to their persistence. The fact that the basic premise of self-development culture is that educators/trainers/coaches dictate the trends and define the criteria for development may raise some doubts. It is important to consider whether we are not subjected to market manipulation in this regard. There is always a risk, when trends are somewhat imposed by those who at the same time help others in the process of self-realization by offering paid training and coaching services. This raises the question whether this is merely an illusion of development supported by those who live off teaching and improving others. 
The media that contribute to creating a culture of development include "developmental" internet portals, social network profiles and fan pages, and theme magazines. All of them are at the same time advertising a variety of development-oriented educational and consulting services. And this is when ethical issues are starting to be involved. They are outside the main scope of this work, so they are not discussed in detail and are left only as signaled. At the same time, the important matter for further consideration is the explanation of what coaching really is.

\section{COACHING VS. MENTORING}

The analysis of the reference books on coaching from the last few years shows that it is much easier to answer the question of what coaching is not than to precisely define it. It may be helpful to consider how coaching differs from other forms of support in development, such as mentoring, tutoring or skills training.

According to the authors of the "Handbook of coaching" - S. Thorpe and J.Clifford - coaching is "the process of helping someone enhance or improve their performance through the reflection on how they apply a specific skill and/or knowledge" (Thorpe, Clifford, 2011, p. 17). Thus, it is a matter of supporting development, and because development is a sequence of changes, hence coaching directly supports the change and reduction of its side effects. A change usually arouses fear and resistance, and coaching is used to overcome this feeling so that one may be able to move forward (Thorpe, Clifford, 2011, p 18).

Mentoring intertwines with coaching in organisations, but in fact it is a much more general notion. It covers a wider range of activities involving giving general remarks and advice on personal and professional life, and in the case of students, the functioning of the school. Frequently the mentor is superior to the student, becomes an authority and a role model. On the other hand, the coach usually occupies equal position to the client/student and this relationship is not as personal (you do not necessarily need to like the coach while the opposite is true for the mentor). In addition, coaching is about specific aims, and mentoring is more about general development (Thorpe, Clifford, 2011, p. 22, Rogers, 2009, pp. 28-29). Both coaching and mentoring may also be present in school environment, where they intertwine and merge.

The tutor, in turn, deals with the development of intellectual abilities by assisting in the implementation of particular projects or simply doing homework, when referring to school reality. Training is the acquisition of new knowledge and skills, while coaching is about improving the skills that the client/pupil already has.

According to Jenny Rogers, the goal of coaching is to work with the client to achieve all of the client's potential - as defined by the client (Rogers, 2009, p 14). The client is a source of resources, and the coach's task is to make the client start using them. This is done by asking the right questions, setting challenges and providing support. A necessary condition for such cooperation is respect and partnership relationship between the coach and the client, but the client must be willing to make changes in his life (Rogers, 2009, pp. 14-15).

There are three basic skills important in coaching: listening, asking questions and giving feedback. The teacher that also wants to be a good coach should acqu- 
ire these skills, and learn, in particular, how to be a good listener and how to ask coaching questions. These are questions that allow the coach/teacher, as well as the coached/the student to see the essence of the problem, to reflect and explain the complexities of the issue analysed in the classroom.

At this point it is worthwhile to pay more attention to the specific ways of using coaching in the classroom.

\section{COACHING IN THE CLASSROOM}

The main aim of this section is to evaluate the usefulness of coaching in the school environment and potential benefits that can be obtained from coaching for students as well as teachers and the entire school staff.

There are some coaching tools that can be used at various stages of the coaching process at school, including the balance wheel, rating scale, bisociation, viewpoints and motivational record.

During training a teacher can learn how to develop classroom practice that supports growth through the use of high level listening, questioning, reflecting and summarizing. As a trainer and a coach trying to be up to date with training trends, I acknowledged that most of professional training programs contain elements listed below:

- $\quad$ using active listening and open questions to tackle issues such as pupil behaviour,

- $\quad$ reaching their full potential by putting in place realistic goals and plans to achieve them,

- taking responsibility for their own progress through change,

- building rapports that can turn previously difficult interactions into productive ones.

The content of the training is most often associated with an analysis of the goals and motives of their implementation, based on the scheme: goal - action - result. A very important matter is always the principles, based on which objectives are formulated. And so teachers learn that beneficial in this process is to adopt a strategy of K. Vonnegut, which is based on imagining the future state, or effect, to which we aspire, and then stepping back from that point in the future, step by step we write down actions that must be taken to achieve that aim. By this means, this writer created the plots for his books, and we can acquire a precise plan of action, located in time. This is a kind of "writing a book backwards" - first we come up with an ending, and then we build up an action going back in time. In addition, coaches/teachers are taught that the goals should be subject to the S.M.A.R.T. principle and should therefore be (Doran, 1981, p. 35-36):

- Specified - precise and containing as much details as possible;

- Measurable - the effect must be measurable and ideally we should be able to express it in numbers;

- Attractive - inspiring and encouraging action, and thus motivating;

- Realistic - achievable for the individual, taking into account personal resources; 
- Time-dependent - with a specified deadline for achieving the goal, which is stimulating.

Specific learning objectives for each lesson should be expressed in the form of outcomes, effects, which means that they should specifically and concretely define what a pupil should be able to do as a result of the classroom process. Furthermore, objectives should be written in a way as to make it possible to determine whether aims have been achieved or not. The teacher/coach should ensure that the goals are rather short-term and set to match the potential of the sources used in the classroom, but also to the capabilities of the teacher and the students. They should also specify the conditions in which the aim is considered achieved as well as the features, events, properties, after which the teacher knows that the objectives have been met.

We can also apply simpler rules for setting correct goals. The conditions listed below work well in the educational practice. According to them, the aim should be:

- precisely defined,

- positive,

- possible to achieve independently,

- ecological.

At the coaching trainings, teachers also learn about supporting children in setting goals. First of all, motivation should be built on the principle of benefits. A child needs our help in creating a vision - defined and precise picture of the future state in the child's imagination. Negative motivation relying on fear of adverse consequences should be avoided; instead the teacher should rather lean more towards positive motivation, "the pursuit of ...". For this, in turn, we need a vision of how life will change when the goal is reached. Attractive vision increases the motivation to achieve aims.

The easiest way to create a vision is to use the tools that stimulate the imagination, i.e. association (according to NLP - imagining yourself inside the situation, seeing with our own eyes), and dissociation (looking at yourself from the outside, from the perspective of the observer), imagining colours and weaving them into visions of all-sensory experience (not only stimulating sight, but also hearing and touch). All this affects the clarity of the vision, and thus increases the motivational effect.

The most effective way of inspiring student's motivation is searching for an answer to the question: "How the thing I am supposed to learn relates to my life objectives?" In this context, the gains and losses need to be analysed after reaching the objective, and an attractive prize should be set up, waiting for the pupil at the end of each stage of learning.

The so-called constructive criticism also helps in effective learning. It is a transfer of information which is designed to change attitudes, behaviour and conduct of another person. We achieve this by letting the interlocutor realize that we are not satisfied with his actions, and by persuading him to change his behaviour or motivate him to greater achievements. We evaluate behaviour, and not the person himself. Properly designed feedback, which is a type of description of human behaviour, will be useful in this situation. Feedback informs people how others perceive their behaviour. Feedback is meant to improve communication and collaboration, to help this person to function better among people, and at the same time not to harm this person. 
- The three main components of feedback are (Sterna, 2012a):

- Reaction to all of the observed behaviour - in this part we tell the other person how we reacted to his action/behaviour and what emotions we feel about such actions;

- The observed positive behaviour - we share what we liked in the behaviour of this person;

The elements that are missing - instead of saying what we did not like, we say what we missed in the behaviour of that person.

For instance, instead of saying: "You say a dozen words in one breath, which makes you talk too fast so I cannot understand you", we can say: "In your speech, I missed pauses between spoken sentences, especially before the words particularly important. If you added them, you would sound calmer and more audible". Students also need to be taught to provide proper feedback on their mutual relations.

The concept of R. Dilts is another useful tool in the arsenal of coaching techniques. In various studies we find slightly different versions of this concept, but basically Dilts distinguished seven levels of personality, also known as the levels of change (Dilts, 2006, p. 27-37):

- level of environment,

- level of behaviours,

- level of states,

- level of abilities and competences,

- level of beliefs and values,

- level of identities,

- level of mission.

Both the positive messages to encourage the actions/changes and the negative messages to discourage actions/changes can be formulated at various, above-mentioned, levels. By referring to specific examples at the behaviours level we can formulate the following statements (Taraszkiewicz, 2008,):

- Peter, if you want make a proper long jump, you need to push off the takeoff board harder just before the jump ...

(Peter gets guidance what to do to complete the task).

- Well, again, you jumped badly!

(Peter gets reprimanded in an unpleasant form, which rather reduces motivation for further tries).

At the level of abilities and competencies it would look as follows:

- Peter, I believe you can jump very well, but you need to push off the board harder...

(Peter receives assurance of his capabilities and specific advice on what he should do).

- How can you not do this simple exercise! You cannot do a thing!

(Peter hears ironic summary of his efforts and generalising remark "you cannot do anything". He will probably always remember that he hates this exercise). 
Message from the level of beliefs and values is as follows:

- Peter, believe me, it's not a very difficult exercise and certainly you are able to make the jump. Try again ...

(Peter hears encouraging assurance to make another attempt, and he feels that the teacher believes in him).

- Oh, my dear, sport is not for you!

(Peter already knows what he is not good at).

While from the identity level we say:

- Peter, you are very physically fit, but you push off the board not hard enough.

(Peter hears the appraisal relating to his identity and a remark to correct specific behaviour).

- Stop trying, you move like a bull in a china shop! You will never be a gymnast!

(Peter is definitely tired of the teacher, jumping, and making any further efforts, probably also exposed to other students laughs as a result of this comment).

Properly formulated feedback can significantly modify the styles of student reactions to success and failure. By formulating negative messages at the behavioural level while expressing positive ones at the level of values and beliefs or at the identity level, we build the strategy of "cognitive optimism." And by doing the opposite, we add to students' attitude of "learned helplessness" (Seligman, 1993, p. 34-53).

Finally, the questions - one of the most important tools in coaching. The school should use the questions that (Sterna, 2012b):

- show pupils a broader perspective of the problem,

- are closely related to the lesson's subject,

- focus on the main issues of a given lesson,

- should trigger interest of students in the topic,

- students should receive answers in the classroom.

Key questions should:

- emphasize the learning objectives and accelerate their implementation,

- stimulate the desire to receive answers,

- $\quad$ engage all students and challenge them,

- encourage students to think for themselves and to seek answers,

- encourage students to justify opinions and their way of thinking.

To create a good key question we need to once again realize what the purpose of the lesson is, think about how this objective is connected to wider knowledge of the world and think about what question would interest students and encourage them to seek answers (Sterna, 2012b).

Examples of key questions are:

English: What skills are necessary to talk to someone about holiday plans?

Science: Why do you think potted plants at our homes are often placed on window sills?

Questions can also be used as tools for active listening. Active listening is about showing your interlocutor with your whole body that you listen to him carefully. 
It allows for the creating of a sense of mutual trust. It can also provide a sense of support. It helps the interlocutor in thorough analysis and organisation of his statement, which increases his chances to solve the problem independently. It gives the opportunity to confront ideas of a certain person with reality and their subsequent correction. It is also a source of feedback. Active listening allows for the following of the reasoning of the other person, his way of thinking and argumentation. A paraphrase also plays an important role in this process. This technique is to repeat in your own words the content of verbal message as well as the message of the accompanying body language. Its essence is to extract the most important information and to obtain confirmation of the sender that our interpretation is consistent with the intent of the interlocutor. Through the use of a paraphrase you can:

- organize your understanding of the recipient,

- organize the thinking of the sender,

- focus the attention of the interlocutor on the topic of conversation,

- slow down the conversation, dampening emotions and allowing time to think,

- express respect for interlocutor,

- adopt common criteria,

- prevent misunderstandings,

- confirm following the train of thought of the participant.

It is worth noting that in professional coaching the paraphrase is not applied, instead backtracking is used, which means the repetition of the exact client's statements. In school education paraphrasing may be more useful, as it allows one to explain better the confusing issues and to agree on a common version of the teacher's and the student's discussed fragment of reality.

In addition to the content of questions and paraphrased answers, the sole technique of asking them is also important. Satisfactory answer requires even about 3 minutes of waiting time. Meanwhile, studies show that teachers are waiting for the answer to their question only 0.9 seconds (Sterna, 2012b). If they do not hear a response within this time, they immediately give it themselves. The benefits of increasing waiting time are measurable. Pupils' responses become longer, the number of cases of non-response is reduced, answering students are more confident, students challenge or refine answers of others and offer more alternative solutions.

Conversations in the classroom and moderating discussions are sometimes called "edu-coaching in practice". The role of the moderator is to look after good relationships between participants, to establish and abide by the rules and procedures of group interactions. The moderator should be aware of the group process, and his task is to lead the process and deal with difficult situations in the group. Other tasks include structuring and proposing collaborative techniques as well as maintaining the level of activity and attention of the group. This function is described well by the concept of facilitation, meaning the phenomenon of accelerating the work of group members due to the very presence of other people. However, there is a difference between the roles that a teacher can adopt in the classroom, i.e. the role of a presenter, a moderator and a facilitator. The moderator must take into account the different dimensions of the work of a group, the task and con- 
tent of the work, the relationships between the members and the dynamics of the group processes. The presenter can only be concerned with the aspect of the content/task, whereas the facilitator mainly about the aspect of the group process, without knowing the details of the work content. Most favourable role then is the one of the facilitator - a person who knows the mechanisms and dynamics of group work, understands and feels its manifestations, knows various techniques of group work and can accurately use them to achieve the aim set by the group. Moderation is close to coaching, but it is not a classic coaching, because it implies a certain (albeit minimal) level of directivity.

During the training of teachers, basic coaching skills are often presented (listening, asking questions, feedback), and the most important determinants of the coaching style of teaching. However, these programs do not always devote a place to the typical coaching tools, which can also be useful in the classroom such as, e.g., the GROW model and tools allowing to accomplish it in practice.

The GROW model is the basic coaching standard developed by John Whitmore. The model's name comes from an acronym created from the first letters of the following stages:

1) Stage 1 - GOAL is about defining aims,

2) Stage 2 - REALITY is the current state of reality, it serves the purpose of resources identification,

3) Stage 3 - OPTIONS concerns recognition of capabilities,

4) Stage 4 - WILL is taking actions.

Such a scheme can be successfully applied during classes. At the GOAL stage, the teacher together with the pupils determine the purpose of the lesson, using previously mentioned rules for purpose formulation, and seek challenging questions related to the objective. At the REALITY stage, the teacher helps students, with carefully selected questions, to check their knowledge and skills that can be useful in solving these problems. In the next stage they search for all the possible options solving the issue, choose the most appropriate one, and take actions to address the issue during the last stage of the process. The whole process resembles the structure of problem-based learning and resource-based learning. What distinguishes the GROW model is the work with questions which are relevant to a particular stage.

Other common tools used in coaching are the various types of wheels and scales. The Wheel of Life is one of these tools, where in 8 areas of life the level of your satisfaction is noted. Another tool is the Wheel of Alternatives, which can be helpful in decision making. On the scales you can select your current position on the way towards achieving the goal.

Furthermore, bisociation or the so-called double thinking, the term coined by Arthur Koestler, should also be included here. This is based on imposing an idea(s) or a technique(s) on other ideas and techniques and thus creating novel concepts, e.g., a mobile phone with a camera. This technique is desirable in the GROW model at the stage of searching for solutions.

Problems in relationships often occur in school reality and then the goal is to organize such relationships. Changing Perspective is one of the techniques to con- 
sider in this kind of situations. The main goal of this exercise is the conviction that our view on the matter (in this case: the relationship with the other person) is just a single, very fragmentary point of view, and is not a complete description of the situation. Only putting yourself in the role of other people allows you to see the broader picture and notice previously unseen elements (Piwowarczyk, 2013).

The described exercise can also be used in situations where the student has to prepare, e.g., a public speech. Three perspectives are usually considered:

- I (my own perspective);

- You (perspective of a second person);

- $\mathrm{He} / \mathrm{she}$ (perspective of an independent observer, e.g., a fly on the wall, figure in an image, etc.).

The second variant of this technique introduces a fourth perspective - the perspective of the system. This may be a classroom or the whole school as an institution (Piwowarczyk, 2013).

\section{BENEFITS OF COACHING}

A student, as well as an employee of an organisation that applies modern methods of skills development feels appreciated, which, in turn, undeniably affects the motivation to learn. A comprehensive approach to potential benefits of coaching at school was presented in the article of Parzeniowska and Serkowska:

Table 1. Benefits of coaching

\begin{tabular}{|c|c|}
\hline For the school & For the teacher \\
\hline $\begin{array}{l}\text { - increase in students' and teachers' } \\
\text { engagement and motivation } \\
\text { - strengthening the culture of mutual } \\
\text { learning and cooperation } \\
\text { - fast error correction } \\
\text { - continuous improvement of } \\
\text { qualifications and the quality of work } \\
\text { - improvement of the image - the school } \\
\text { as an institution that learns }\end{array}$ & $\begin{array}{l}\text { - systematic structured reflection on the } \\
\text { quality of his own work } \\
\text { - increase in practical competence } \\
\text { - enhancing the relationship with the } \\
\text { environment, a sense of support } \\
\text { - better contact with students and greater } \\
\text { satisfaction with their results } \\
\text { - prevention of professional burnout }\end{array}$ \\
\hline For the student & For parents \\
\hline $\begin{array}{l}\text { - strengthening self-esteem } \\
\text { - development of learning skills and self- } \\
\text { control } \\
\text { - increase in motivation to learn } \\
\text { - progress in learning } \\
\text { - decrease in stress level } \\
\text { - increase in trust in the teacher and } \\
\text { intensification of contacts }\end{array}$ & $\begin{array}{l}\text { - increase in students' and teachers' } \\
\text { engagement and motivation } \\
\text { - development of skills supporting } \\
\text { children in learning } \\
\text { - better understanding of the situation of } \\
\text { the child in school } \\
\text { - better cooperation and deeper relations } \\
\text { with the teacher } \\
\text { - better awareness of ongoing processes } \\
\text { and crises of development to which the } \\
\text { child is subject at a given stage }\end{array}$ \\
\hline
\end{tabular}

Source: Parzeniowska J., Serkowska W., Coaching - nowe słowo na określenie znanej metody, 
„Edukacja i Dialog", nr 191/2005, http://www.eid.edu.pl/archiwum/2005,103/padziernik,212/ coaching_-_nowe_slowo_na_okreslenie_znanej_metody,1838.html, 24.02.2013.

Not only do children benefit from an application of coaching methods in school learning process, but also their parents. For students, these benefits can have a very wide dimension as strengthening self-esteem and development of learning skills and self-control can affect their whole future life.

In addition to the obvious benefits listed in the table, for the whole school environment the use of coaching in education can also be successfully justified by referring to contemporary theories of learning.

\section{THE ESSENCE OF THE LEARNING PROCESS AND THE USEFULNESS OF COACHING}

According to the concept of K. Illeris (2006), the learning process integrates three dimensions: the cognitive, the emotional and the social. It comprises the processes of interaction between an individual and the material and social environment and internal mental processes associated with knowledge acquisition. The main categories of interactive processes important to the dynamics of the learning process can be characterised as perception, transmission, experience, reflection, activity and participation. These categories should not be treated as separate, because they merge with each other to varying degrees in individual acts of learning and cognitive situations (Illeris, 2006, pp. 241-242). Internal mental processes can be cumulative (mechanical), assimilative (additive) or accommodative (transgressive). Through cumulative processes new knowledge structures and patterns of behaviour are acquired. New components are added to existing structures through the processes of assimilation. Accommodation processes are set to disintegrate and reconstruct existing structures and patterns. They occur when an individual encounters stimuli that cannot be assimilated with the existing structures and patterns. The reconstruction of knowledge taking place in the process of accommodation may be either offensive or defensive. Learning processes may also be associated with a variety of situations and events. These can be small events in narrow areas of realit, as well as events of a wider range, encompassing the whole personality and identity of an individual. They all contain the elements of cognitive, emotional and social dimensions in different proportions. Learning takes place in phases, which are situated between the stable development based on assimilation, and characteristic developmental "jumps", often of accommodative nature. There are also special or even crisis situations, which may lead to deep, holistic, transformative processes that involve changes in all three dimensions of learning and strongly affect the identity of the learner. Therefore, the transformation processes are enhanced by simultaneously occurring accommodative processes (Illeris, 2006, pp. 241-245).

The structure of a learning process of this type is shown figure 1.

Coaching can facilitate accommodative processes when there is a reconstruction of knowledge. This is especially important when we realize that some learning processes contain active resistance, rejection, blocking or distorting of knowledge. This is because the information that stays in conflict with the existing structures and potentially could initiate accommodative processes is most often transformed 
in a way that assures the disappearance of all contradictions and assimilation of knowledge (Illeris, 2006, pp. 242-244). This process is much easier and less energy-intensive than accommodation and subsequent entry into transgression level. This is where coaching could be potentially useful. It seems to be an important tool in overcoming the resistance of the learner by making changes at deep neurological levels (Dilts, 2006, p. 27-37), i.e. the level of values and beliefs, and identity and vision. When a person learns something new, he has a strong temptation to turn it into something that he already is familiar with. Coaching can help in overcoming all obstacles and fears in this space, to freely learn new things and incorporate them in the structure of personality. Thereby, coaching may contribute to a more

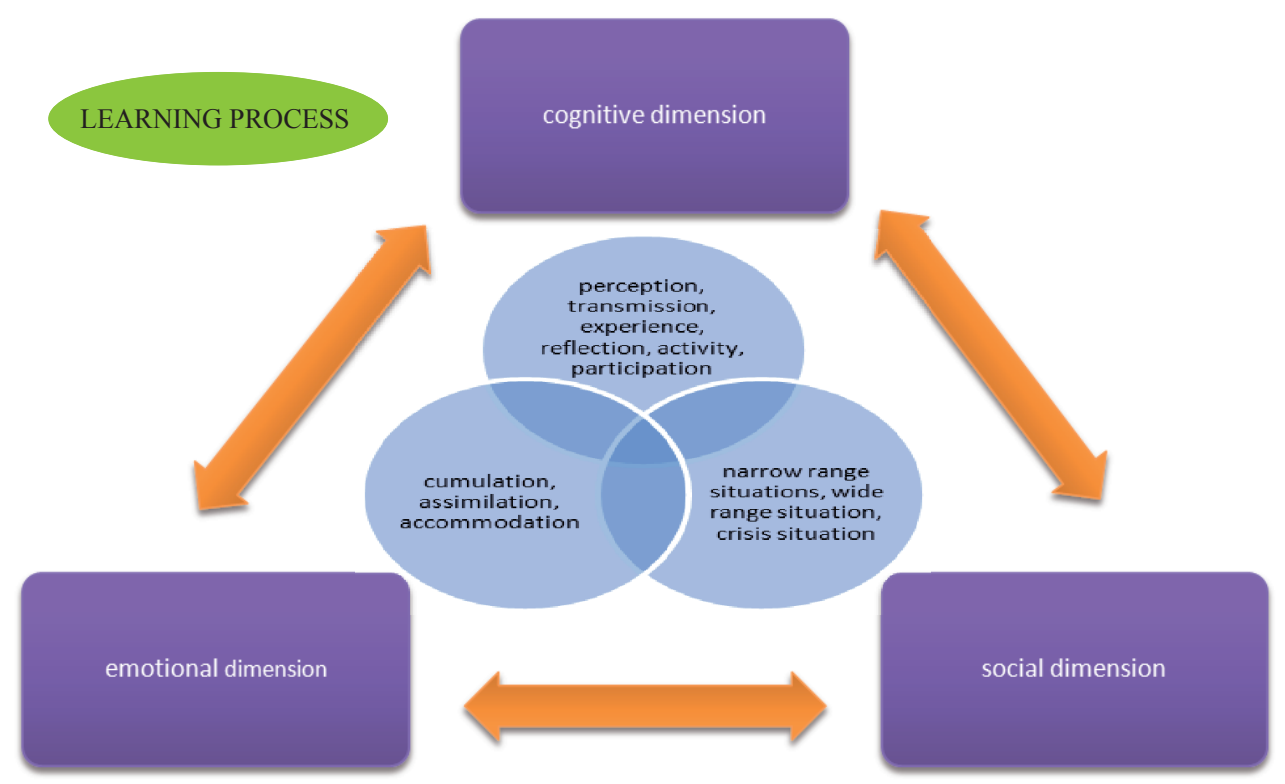

complete development of the students, which is inherently connected with better mood and the achievement of personal satisfaction.

Figure 1. The learning process according to K Illeris.

Source: Own study based on: Illeris, K. (2006). Three Dimensions of Learning. Wrocław. Wyd. Naukowe DSWE.

\section{SELF-DEVELOPMENT CULTURE IN THE CLASSROOM - SNOBBERY OR NECESSITY?}

When considering using coaching at school, a few questions occur. Can a teacher also be a good coach? Is it worthwhile to implement coaching in the education system? How can coaching help to improve classroom management?

Undoubtedly, the use of basic tools of coaching in teaching increases student motivation. It causes interest in the subject, and thus increases the speed of learning and facilitates memorizing. What is also important is that the knowledge 
conveyed in this way is always connected to experience - during the formulation of the objective, resources evaluation and generating solutions. Therefore, it is not a matter of a coaching trend in education, but of really competently used tools that can enhance traditional classes or be a perfect expansion involving problem solving, if the teacher has applied these methods earlier.

Certainly, these solutions coming straight from the commercial training market should be used in the school reality as they increase the efficiency of the teaching process and make it more enjoyable. The teacher acquires effective tools to attract students' attention, so he does not need to force the attention in the classroom through a system of external motivators, i.e. rewards and punishments, or by the use of complicated rules and methods of disciplining students. Discipline is no longer needed where cognitive curiosity is born and these are the precise assumptions of coaching methods.

Even a class-lesson system common in most schools shouldn't be a problem. Theoretically it is possible to complete the coaching process in 45 minutes, but detailed planning is necessary. A teacher-coach doesn't have much space to improvise when it comes to the elements of the coaching process. Here the GROW model seems to be really useful. However, the teacher's creativity is essential to ask the right questions inside the subsequent stages of the process.

The only doubt that remains is the range of subjects in coaching trainings for teachers. Not all of the trainings offer the most important model of coach work the GROW or tools often used in professional coaching, such as wheels, scales, and change of perspective. Moreover, to use successfully all the coaching tools "the coach identity" is needed. Simply, a teacher should internalize most of the coaching principles and skills to really make use of them at work. A good edu-coaching training course for the teachers should contain not only mechanically transmitted knowledge and perfectly rehearsed techniques, but also the elements of changing attitudes to learning. The teachers should be convinced that coaching is really efficient as a way of learning.

Considering the present situation of the whole educational system, implementing coaching in education surely is an interesting proposition. Coaching skills may help teachers to create self-development culture in their classrooms and liberate students' potential and creativity, and it is possible when coaching becomes a way of life and thinking about reality. Using coaching methods at school and being a coach for the students may also be beneficial for the teachers themselves. They can reach their goals more easily, plan their carrier and avoid the professional burnout syndrome. In this particular case the important condition for success is to regularly use coaching as a client and supervision as a teacher. It is rather easy to find your own life/carrier coach. The best training courses give also a chance to be supervised at work with children. It is highly recommended to check it before the training.

Therefore, in order not to become victims of training trends, teachers should first of all check the range of subjects offered by a particular training. It is important not to be deceived by attractive marketing names. An offer whose name contains the word "coaching" often has very little in common with actual coaching. However, thorough analysis of the training program and then the opinion of the 
participants of previous editions should provide sufficient knowledge to allow for an assessment of the real value of the offer.

\section{REFERENCES}

Dilts, R. (2006). Od przewodnika do inspiratora, czyli coaching przez duże "C". Warszawa. PINLP.

Doran, G. (1981). There's a S.M.A.R.T way to write management's goals and objectives. "Management Review" vol. 70.

Giddens, A. (2012). Socjologia, Warszawa: Wydawnictwo Naukowe PWN

Illeris, K. (2006). Three Dimensions of Learning. Wrocław. Wyd. Naukowe DSWE.

Parzeniowska, J., \& Serkowska, W. (2005). Coaching - nowe stowo na określenie znanej metody, „Edukacja i Dialog", nr 191. Retrieved from http://www.eid.edu.pl/archiwum/2005,103/padziernik,212/ coaching_-_nowe_slowo_na_okreslenie_znanej_metody,1838.html.

Piwowarczyk B. (2013). Narzędzia w pracy coacha - Zmiana Perspektywy. Retrieved from http://www. treco.pl/wiedza/artykuly-szczegoly/id/1288/narzedzia-w-pracy-coacha-zmiana-perspektywy.

Rogala-Marciniak, S., \& Marciniak, Ł. T. (2012). Coaching. Zbiór narzędzi wspierania rozwoju. Warszawa: Wolters Kluwer Polska.

Rogers, J. (2009). Coaching. Sopot: GWP.

Seligman, M. (1993). Optymizmu można się nauczyć. Jak zmienić swoje myślenie i swoje życie. Poznań: Media Rodzina.

Sterna D. (2012a). O informacji zwrotnej. Website of the Center for Citizenship Education.Retrieved from http://www.ceo.org.pl/pl/ok/news/o-informacji-zwrotnej.

Sterna D. (2012b). Ocenianie ksztattujace: Technika zadawania pytań. Pytania kluczowe. Book 6., Retrieved from www.ceo.org.pl/pl/o-nas/publikacje-ocenianie\%20ksztaltujace.

Taraszkiewicz M. (2008). Miniporadnik dla rodziców - dodatek do publikacji „Bezpieczna i przyjazna szkota”. Retrieved from http://www.wsip.pl/dodatki/bezpieczna_i_przyjazna_szkola.

Thorpe, S., Clifford J. (2011). Podręcznik coaching. Podręcznik szkolenia. Niezbędnik dla instruktorów i menedżerów. Poznań: Dom Wydawniczy Rebis.

Website of the Regional Labour Office in Lodz, Retrieved Februaty 24, 2013, from http:/ / www.wup. lodz.pl/files/ciz/ciz_Nowoczesne_formy_rozwoju_pracownika.pdf.

Whitmore, J. (2011). Coaching. Trening efektywności. Warszawa: G+J Gruner\&Jahr. 